\title{
Comparative evaluation of Western Blotting in hepatic AND PULMONARY CYSTIC ECHINOCOCCOSIS
}

\author{
AKISU C.*, DELIBAS S.B.*, BICMEN C.**, OZKOC S.*, AKSOY U.* \& TURGAY N.***
}

\section{Summary:}

Many serological tests are widely used in the diagnosis of cystic echinococcosis (CE), caused by the larval stages of Echinococcus granulosus. The present study was carried for differentiation between hepatic and pulmonary cystic echinococcosis by Western Blotting (WB). A total of 121 sera from patients with hepatic CE (37), pulmonary CE (31) and controls (53; consisting of six healthy, seven Hymenolepis nana infection, 20 hepatic and 20 pulmonary diseases other than CE) were examined. In all of the CE patients, E. granulosus infection was confirmed by surgical intervention. Sera were previously tested using $I H A$ and ELISA to detect the E. granulosus specific antibodies. Sera from hepatic cases of CE reacted with 16 polypeptides of 6-1 $16 \mathrm{kDa}$ and sera from pulmonary cases of $C E$ reacted with 14 polypeptides of 4-130 kDa by Western Blotting. The WB test enabled the detection of antibodies in the hepatic CE samples for proteins of $24,32-34,44-46$ and $52-54 \mathrm{kDa}$ in molecular weight in $78.4 \%, 75.7 \%, 78.4 \%$ and $89.2 \%$ of the patients, respectively. In the pulmonary CE samples sera WB test enabled the detection of antibodies 24, 44-46, 100, 110,116 and $120-124 \mathrm{kDa}$ in molecular weight in $81.3 \%, 75.0 \%, 87.5 \%$, $71.9 \%, 84.4 \%$ and $65.6 \%$ of the patients, respectively. We indicated that the antigenic components of high molecular weight can be good candidates for differentiation of hepatic CE from pulmonary CE.

KEY WORDS : cystic echinococcosis, Echinococcus granulosus, hepatic, pulmonary, Western Blotting, IHA, ELISA.

$\longrightarrow$ ystic echinococcosis (CE), caused by the larval stages of Echinococcus granulosus, is still a significant public health problem and also endemic in Turkey (Altintas, 2003). The diagnosis of CE in human is usually by different imaging methods, such as radiology, ultrasonography, computed tomography and magnetic resonance imaging (McManus et al., 2003). Different conventional serological techniques for

\footnotetext{
* Dokuz Eylul University, Medical Faculty, Department of Parasitology, Izmir, Turkey.

** Training and Research Hospital for Chest Diseases and Chest Surgery, Izmir, Turkey.

***: Ege University, Medical Faculty, Department of Parasitology, Izmir, Turkey.

Correspondence: Ciler Akisu M.D., Dokuz Eylul University, Medical Faculty, Department of Parasitology, 35340 Inciralti-Izmir, Turkey. Tel.: +902324124540 - Fax: +902322590541.

E-mail: ciler.akisu@deu.edu.tr
}

Résumé : ÉTUde SÉROLOGIQUE COMPARATIVE DE KYSTES HYDATIQUES HÉPATIQUES ET PULMONAIRES PAR WESTERN BLOT

Plusieurs tests sérologiques sont couramment utilisés pour le diagnostic du kyste hydatique (KH) qui est dû au développement de la larve d'Echinococcus granulosus. La présente étude avait pour objectif de différencier par Western blot (WB) les kystes de localisations hépatique et pulmonaire. 121 sérums provenant de 37 patients porteurs d'un kyste à localisation hépatique, de 31 à localisation pulmonaire, et de 53 contrôles /six supposés sains, sept porteurs d'Hymenolepis nana, 20 atteints d'une affection hépatique et 20 d'une affection pulmonaire autre qu'un kyste hydatiquel ont été axaminés. Chez tous les patients porteurs d'un $\mathrm{KH}$, l'infection par E. granulosus a été confirmée par l'intervention chirurgicale. Les sérums ont été testés auparavant par IHA et ELISA à la recherche d'anticorps spécifiques. Les sérums des $\mathrm{KH}$ hépatiques ont réagi au WB avec 16 polypeptides de 6$116 \mathrm{kDa}$ et ceux des $\mathrm{KH}$ pulmonaires avec 14 de 4-130 kDa. Le WB a permis la détection d'anticorps en cas de KH hépatique pour des protéines de poids moléculaire de 24, 32-34, 44-46 et $52-54 \mathrm{kDa}$ chez 78,4\%, 75,7\%, 78,4\% et 89,2\% des patients, respectivement, et, en cas de $\mathrm{KH}$ pulmonaire, de protéines de 24,44-46,100, 110,116 and 120-124 kDa chez $81,3 \%, 75,0 \%, 87,5 \%, 71,9 \%, 84,4 \%$ et $65,6 \%$ des patients, respectivement. Nous avançons que les fractions antgéniques de haut poids moléculaire peuvent être de bons candidats pour la différenciation des $\mathrm{KH}$ hépatiques et pulmonaires.

MOTS CLÉS : kyste hydatique, Echinococcus granulosus, foie, poumon, Western blot, IHA, ELISA.

the diagnosis of human CE have been developed. But, their diagnostic value in suspected cases of $\mathrm{CE}$ is limited because of the variable sensitivity and specificity (Carmena et al., 2006). Therefore, use of confirmation test such as WB (Western Blotting) is very important in serodiagnosis of CE (Doiz et al., 2001). The hydatid cysts of E. granulosus tend to form in the liver (50-70\%) or lung (20-30\%) but may be found in any organ of the body $(<10 \%)$, including brain, heart and bones (Schantz \& Gottstein, 1986). The sensitivity and specificity of serological tests vary depending on the localization of hydatid cysts. The indirect hemagglutination test (IHA) and the enzyme-linked immunosorbent assay (ELISA) using E. granulosus hydatid fluid antigen are more sensitive for hepatic cases, than pulmonary cysts (Force et al., 1992). On the other hand, sensitivity of WB antigenic bands also appears 
to be more important for hepatic CE (Verastegui et al., 1992).

The aims of this present study were to assess the diagnostic sensitivity and specificity of WB in patients with liver and pulmonary $\mathrm{CE}$ and to compare the antigenic bands that were obtained by WB in both localizations.

\section{MATERIALS AND METHODS}

\section{ANTIGEN}

T he hydatid cyst fluid (HCF) was collected from fertile liver cysts obtained from one E. granulosus infected sheep in Izmir, Turkey. The fluid was clarified by centrifugation at 3,000 $\mathrm{g}$ for $30 \mathrm{~min}$, and the supernatant was stored at $-20^{\circ} \mathrm{C}$ until use as crude antigen. The optimal protein concentration was $10 \mu \mathrm{g} /$ $\mathrm{ml}$ for in-house ELISA and $100 \mu \mathrm{g} / \mathrm{gel}$ for WB.

\section{SERUM SAMPLES}

A total of 121 serum samples were studied, aged 18-77 years (average 49.8). Serum samples were obtained from 37 surgically confirmed hepatic CE patients and 31 surgically confirmed pulmonary CE patients (without other organ involvement). All blood samples were drawn before the surgical intervention. Sera used to assess cross-reactivity were selected from six healthy individuals, seven patients with Hymenolepis nana infection, 20 patients with other proven pulmonary diseases (eight bronchopulmonary cancer, seven pulmonary tuberculosis, five chronic obstructive pulmonary disease) and 20 patients with other proven hepatic diseases (seven hepatocarcinoma, seven cirrhosis, six chronic hepatitis). All the sera were tested previously by in-house IgG ELISA and commercial hydatidosis IHA kit to detect the antibodies against CE. All sera were stored at $-80^{\circ} \mathrm{C}$ until use. The study was approved by the local ethical committee.

\section{INDIRECT HAEMAGGLUTINATION (IHA)}

The IHA assay for echinococcosis was performed according to the manufacturer's instructions (Hydatidose, Fumouze Laboratoires, France). The IHA titers $\leq 160$ were considered negative.

\section{ENZYME-LINKED IMMUNOSORBENT ASSAY (ELISA)}

An ELISA test was performed as described previously (Coltorti, 1986). Microtiter plates with 96-flat bottom wells were used. Each well was sensitized for over night at $+4^{\circ} \mathrm{C}$ with $100 \mu \mathrm{l}$ of $15 \mu \mathrm{g} / \mathrm{ml}$ HCF antigen diluted in phosphate-buffer ( $\mathrm{pH} 7,4)$. After incubation, plates were washed three times with PBS containing $0.05 \%$ Tween-20 (PBS-T). One hundred $\mathrm{ml}$ of the test or control sera diluted 1:100 in PBS-T were then placed in wells in duplicate. Next, the plates prepared were incubated in a moist chamber at $37^{\circ} \mathrm{C}$ for $60 \mathrm{~min}$. They were then emptied and washed again three times with PBS-T. Then, each well was filled with $100 \mu$ conjugate (anti-human IgG conjugated with alkaline phosphatase), diluted with PBS-T at the optimal concentration (1:10000). The plates were again incubated in a moist chamber at $37^{\circ} \mathrm{C}$ for $60 \mathrm{~min}$, after which the wells were emptied and washed once more three times with $100 \mu \mathrm{l}$ PBS-T. Following this, each well was filled with $100 \mu \mathrm{l}$ of the substrate indicator reagent (pNPP, p-Nitrophenyl Phosphate) and incubated for exactly $15 \mathrm{~min}$ at room temperature. The readings were taken at $405 \mathrm{~nm}$. The serum dilutions that resulted in an absorbance at three times the mean absorbance of wells containing negative control samples were considered as positive.

\section{SODIUM DODECYL SULFATE-POLYACRYLAMIDE GEL ELECTROPHORESIS (SDS-PAGE) AND Western Blotting (WB)}

The HCF was solubilized in sample buffer (10\% sodium dodecyl sulphate, glycerol, $1 \mathrm{M}$ Tris, $2 \%$ bromphenol blue). Antigen, approximately $100 \mu g$ protein per gel, was separated by electrophoresis in a $10 \%$ sodium dodecyl sulphate-polyacrylamide gels (SDS-PAGE) according to Wen \& Craig (1994). Separated proteins were electrophoretically transferred onto nitrocellulose membrane. The membranes were blocked in Trisbuffered saline (TBS) (0.1 M Tris, $0.15 \mathrm{M} \mathrm{NaCl}$ ) containing $3 \%$ bovine serum albumin for overnight, washed three times with TBS containing $1 \%$ Tween 20(TBS-T) and cut into strips. The strips were incubated with sera diluted 1:100 in TBS for $1 \mathrm{~h}$ at room temperature. After washing with TBS-T, the strips were incubated in a 1:5000 dilution of goat anti-human IgG alkaline phosphatase conjugate (Sigma A3187) in TBS and incubated for $1 \mathrm{~h}$ under the same conditions. After a new washing cycle, the specific antigenic bands were visualized by the addition of BCIP/NBT (Bromo-4-chloro-3-indolyl Phosphate/Nitro Blue Tetrazolium) alkaline phosphatase substrat (Sigma B-5655). The reaction was stopped with distilled water. The molecular sizes of the bands were evaluated by comparison with a low molecular weight marker (Biorad 161-0305).

\section{STATISTICAL ANALYSIS}

The molecular weight of each band seen in WB was calculated by Win Curve Fit computer program. The data obtained were evaluated by windows 13.0 SPSS program. ROC curve analysis was done for comparison of the bands. The Kruskal-Wallis test, Mann-Whitney $\mathrm{U}$ test and Discriminant analysis were used to determine 
significant differences of molecular weights of the bands between pulmonary and hepatic hydatid cysts and control groups.

\section{RESULTS}

\section{Diagnostic value of ELISA, IHA AND WB}

The sensitivity and the specificity of the tests performed for evaluation of hepatic and pulmonary CE were shown in Table I. IgG serum antibodies reactive against echinococcosis were detected in two patients other than CE (one bronchopulmonary cancer and one cirrhosis) by ELISA, three patients (two bronchopulmonary cancers and one cirrhosis) by IHA and two patients (one bronchopulmonary cancer and one cirrhosis) by WB.

\section{RESUlTS OF WB}

Figure 1 shows the immune response pattern of six hepatic and six pulmonary CE serum samples by WB. Sera from hepatic cases of CE reacted with 16 polypeptides of 6-116 $\mathrm{kDa}$ and also sera from pulmonary cases of CE reacted with 14 polypeptides of $4-130 \mathrm{kDa}$ (mean, 9,6 versus 7,8 bands). WB analysis of pulmonary and hepatic CE sera indicated that some bands have high sensitivity and specificity. To calculate specificity of bands, all sera except study sera were taken

\begin{tabular}{ccccccccc}
\hline & \multicolumn{3}{c}{ Hepatic CE } & & \multicolumn{3}{c}{ Pulmonary CE } \\
\cline { 2 - 3 } & IHA & ELISA & WB & & IHA & ELISA & WB \\
\hline Sensitivity (\%) & 86.5 & 97.3 & 94.6 & & 80.6 & 87.1 & 90.3 \\
& $(32 / 37)$ & $(36 / 37)$ & $(35 / 37)$ & & $(25 / 31)$ & $(27 / 31)$ & $(28 / 31)$ \\
Specificity (\%) & 96.9 & 96.9 & 96.9 & 93.9 & 96.9 & 96.9 \\
& $(32 / 33)$ & $(32 / 33)$ & $(32 / 33)$ & & $(31 / 33)$ & $(32 / 33)$ & $(32 / 33)$ \\
\hline
\end{tabular}

Table I. - The sensitivity and specificity of the tests performed for evaluation of hepatic and pulmonary $\mathrm{CE}$. as control group, including the other localization of hydatid cysts. The area under curve (AUC) values of some bands were determined using the ROC curves (Table II). The bands of $24 \mathrm{kDa}$ and/or $32-34 \mathrm{kDa}$ were detected in all hepatic CE patients. The bands of $100 \mathrm{kDa}$ and/or $120-124 \mathrm{kDa}$ appeared in all pulmonary CE patients except one. The $100 \mathrm{kDa}$ and $120-$ $124 \mathrm{kDa}$ bands had $79.7 \%$ and $73.3 \%$ AUC values, respectively $(\mathrm{p}<0.001)$.

According to the discriminant analysis of the bands, WB had $94.6 \%$ sensitivity and $96.9 \%$ specificity for hepatic CE and $90.3 \%$ sensitivity and $96.9 \%$ specificity for pulmonary CE. The two discriminant functions produced according to the molecular weights of the bands correctly classified $93.4 \%$ of the cases (Fig. 2).

\section{DISCUSSION}

T The intensity of the serologic response to hydatid antigens varies considerably depending on the host and location of parasitic cysts. Pulmonary cysts usually yield low serologic response, whereas the hepatic cysts are usually accompanied by a sustained serological response (Zarzosa et al., 1999). In this study, the sensitivities of all tests performed for patients with pulmonary $\mathrm{CE}$ are lower than that performed for patients with hepatic CE. The least sensitive test is IHA in both organ involvements. The sensitivity results obtained from IHA test are similar to those obtained by others (Gadea et al., 1999; Todorov et al., 2003). Although, ELISA was indicated as highly sensitive (100\%) in detecting anti-Echinococcus antibodies irrespective of the site of the cyst localization (Wattal et al., 1986), many authors reported ELISA not to be good enough to detect low antibody levels produced in pulmonary CE. Our ELISA results are similar to those obtained by Zarzosa et al. (1999).

\begin{tabular}{|c|c|c|c|c|c|c|}
\hline \multirow{2}{*}{$\begin{array}{c}\text { Molecular } \\
\text { weight } \\
\text { (kDa) }\end{array}$} & \multicolumn{3}{|c|}{ Hepatic CE } & \multicolumn{3}{|c|}{ Pulmonary CE } \\
\hline & $\begin{array}{c}\text { Sensitivity } \\
(\%)\end{array}$ & $\begin{array}{l}\text { Specificity* } \\
(\%)\end{array}$ & $\begin{array}{c}\text { Area Under } \\
\text { Roc Curve (\%) }\end{array}$ & $\begin{array}{c}\text { Sensitivity } \\
(\%)\end{array}$ & $\begin{array}{l}\text { Specificity* } \\
(\%)\end{array}$ & $\begin{array}{c}\text { Area Under } \\
\text { Roc Curve (\%) }\end{array}$ \\
\hline $10-12$ & 37.8 & 70.2 & 54.0 & 56.3 & 76.4 & 66.3 \\
\hline 24 & 78.4 & 66.7 & 72.5 & 81.3 & 65.2 & 73.2 \\
\hline $32-34$ & 75.7 & 65.5 & 70.6 & 56.3 & 56.2 & 56.2 \\
\hline $44-46$ & 78.4 & 41.7 & 60.0 & 75.0 & 39.3 & 57.2 \\
\hline $52-54$ & 89.2 & 40.5 & 64.8 & 46.9 & 23.6 & 35.2 \\
\hline 100 & 29.7 & 50.0 & 39.9 & 87.5 & 71.9 & 79.7 \\
\hline 110 & 32.4 & 59.5 & 46.0 & 71.9 & 74.2 & 73.0 \\
\hline 116 & 40.5 & 42.9 & 41.7 & 84.4 & 59.9 & 72.0 \\
\hline $120-124$ & 13.5 & 60.7 & 37.1 & 65.6 & 80.9 & 73.3 \\
\hline
\end{tabular}

* To calculate the specificity of bands, all sera except study sera were taken as control group, including the other localization of hydatid cysts.

Table II. - The area under curve values, the sensitivity and the specificity of several bands detected in sera of pulmonary and hepatic CE by WB. 
Hepatic CE

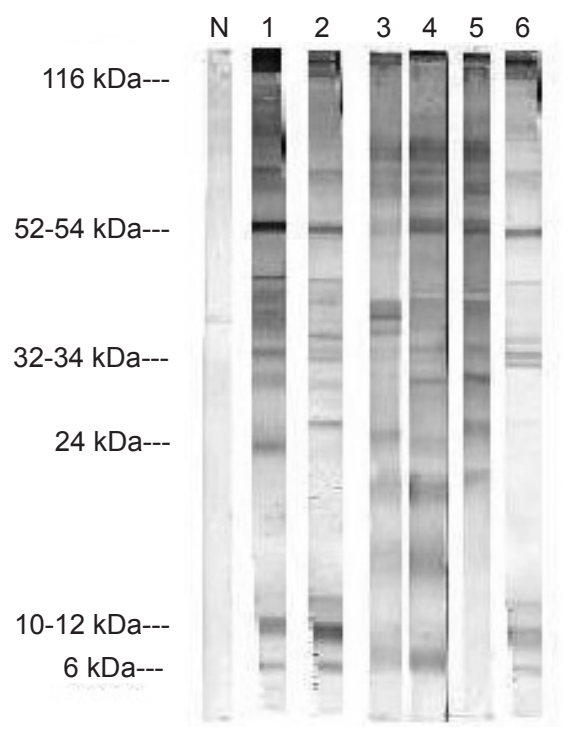

\section{Pulmonary CE}

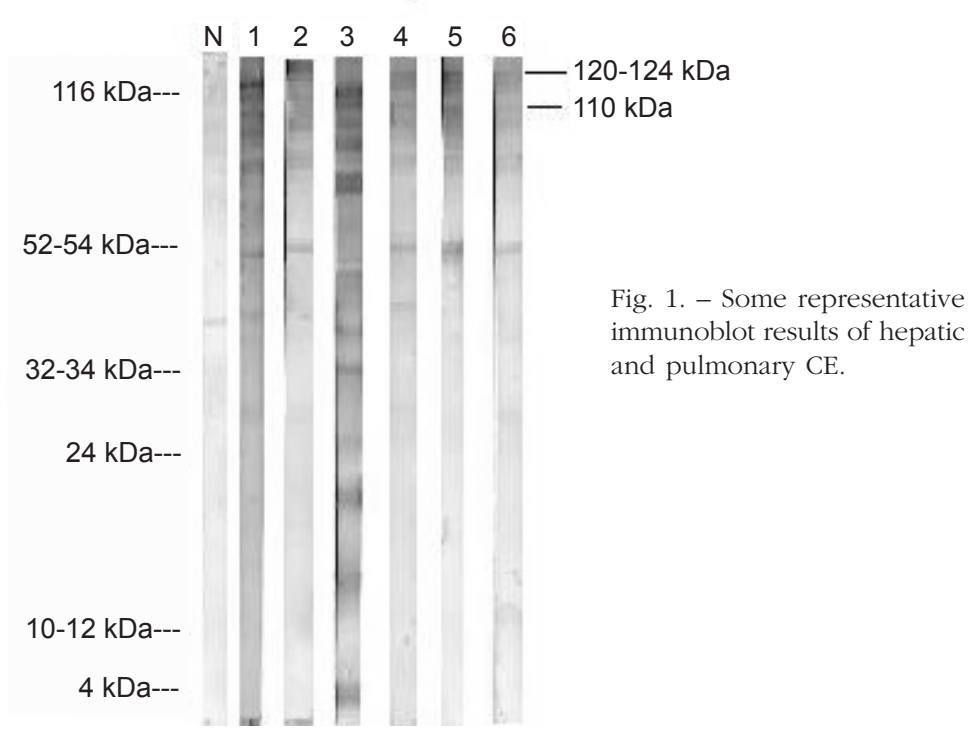

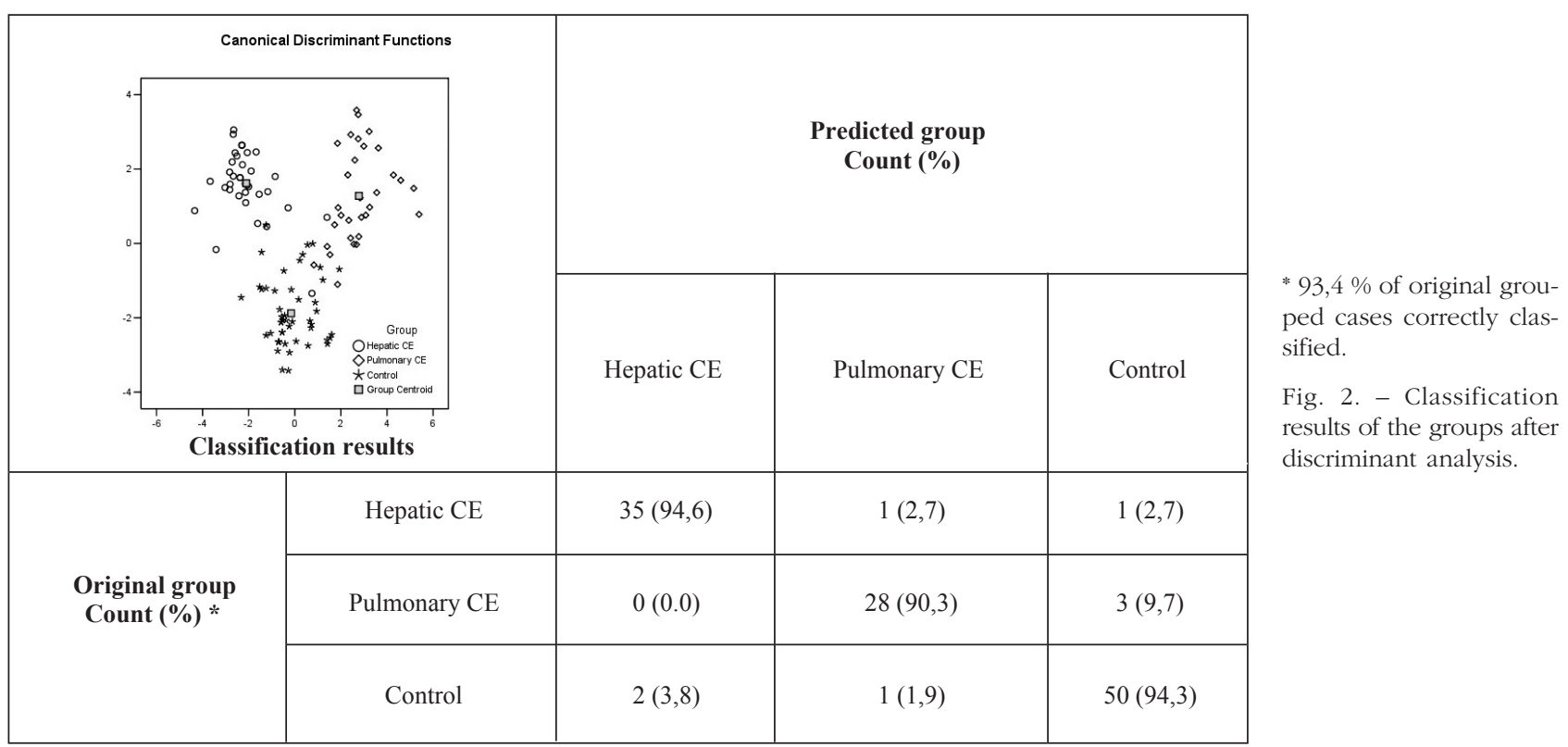

In our WB, we could not get sensitivity or specificity results higher than $90 \%$ for single bands, despite the high sensitivity and specificity results obtained with antigen 5 or antigen B by others (Kanwar et al., 1992; Sbihi et al., 1997). The discrepancy may be attributed to the differences in using purified antigen or electrophoresis conditions. The sensitivity of the WB in our study is similar that described by Li et al. (2004) who similarly used HCF as antigen in WB. But when whole larval extract is used in WB assay, higher sensitivity is observed (Liance et al., 2000). The sensitivity results in WB obtained from hepatic CE appears slightly higher than that of obtained from pulmonary CE. Although the most sensitive band in the WB of hepatic $\mathrm{CE}$, according to the ROC curve analysis, is $52-54 \mathrm{kDa}$, it seems to have little importance, in differentiating pulmonary and hepatic CE. Similarly, despite the relatively high sensitivity of the other bands of intermediate molecular weight (24 kDa, $44-46 \mathrm{kDa}$ ) as has been observed by others (Kanwar et al., 1992; Doiz et al., 2001), these bands did not allow differentiation between hepatic and pulmonary CE. Although some authors showed relatively high sensitivity for the 10 to $12 \mathrm{kDa}$ protein, the smallest subunit of the B antigen (Verastegui et al., 1992; Doiz et al., 2001), in our investigation, this band presented lower sensitivity for detection of CE cases. Our data showed that high molecular weight antigenic components are important in CE cases. According to the ROC curve analysis, the bands in the range of $100 \mathrm{kDa}$ and $124 \mathrm{kDa}$ can be candidates for differentiation of 
pulmonary CE from hepatic CE. The polypeptide of $100 \mathrm{kDa}$ was recognized in WB assay by the 27 of 31 patients with pulmonary CE $(87.1 \%)$, but only by the 11 of 37 patients with hepatic CE $(29.7 \%)$. We also found a sensitivity of $70.9 \%$ in $110 \mathrm{kDa}$ band in pulmonary hydatidosis in contrast with $32.0 \%$ in hepatic CE and a sensitivity of $83.9 \%$ against $40.5 \%$ in hepatic CE in $116 \mathrm{kDa}$. According to the ROC curve analysis, the band of $120-124 \mathrm{kDa}$ is observed as the most important band for differentiation. There aren't enough studies about high molecular masses in CE patients (Sbihi et al., 1997; Kanwar et al., 1992; Shambesh et al., 1995). In a previous study, we frequently found a band of $124 \mathrm{kDa}$ in patients with pulmonary CE (Akisu et al., 2005). Evidence for strain diversity based on morphological, biological and biochemical features of E. granulosus species has been principally confirmed by recent genetic studies (McManus, 2006). HCF also differs qualitatively and quantitatively depending on cyst location such as pulmonary cysts give poor quality antigens (Biava et al., 2001) and host origin such as HCF from human origin triggers a relatively stronger positive reaction due to higher protein concentration (Mamuti et al., 2002). Also, the sera of patients from different geographic foci might have different specials (McManus, 2006). Indeed, detection of the high molecular weight bands in pulmonary CE that is not reported by other studies might be attributed to sera of patients obtained from a different focus, Turkey.

In our study, discriminant analysis of WB bands for hepatic and pulmonary CE revealed $94.6 \%$ and $90.3 \%$ sensitivity, respectively. According to discriminant analysis, bands obtained by WB in patients with CE allow to detect the localization. Gadea et al. (1999) reported that when a discriminant analysis was applied by using the linear functions of the bands instead of analyzing the different bands separately, the sensitivity of WB was increased, without a notable loss of specificity. In that report WB coupled with a discriminant analysis showed $100 \%$ sensitivity for hepatic CE but was unsuccessful for the diagnosis of infection in one patient with pulmonary CE. In our study, discriminant analysis of WB bands for both hepatic and pulmonary localization showed $96.9 \%$ specificity. But, the occurrence of false positive results in patients with other parasitic infections like alveolar echinococcosis and fascioliasis should be studied for real assessment of WB specificity.

The present study intended to evaluate the usefulness of immunoblot analysis for diagnostic verification of human CE either located in liver or lung. It would be important to see high molecular weight bands in WB for confirmation of conventional serology in pulmonary $\mathrm{CE}$ cases, in addition to detection of antigen $\mathrm{B}$ and antigen 5 components.

\section{REFERENCES}

Akisu C., Bayram Delibas S., Yuncu G., Aksoy U., Ozkoc S., Bicmen C., Sevinc S. \& Yaldiz S. Evaluation of IHA, ELISA and Western Blot tests in diagnosis of pulmonary cystic hidatidosis. Tuberkuloz ve Toraks, 2005, 53, 156-160.

Altintas N. Past to present: echinococcosis in Turkey. Acta Tropica, 2003, 85, 105-112.

Biava M.F., DaO A. \& Fortier B. Laboratory diagnosis of cystic hydatid disease. World Journal of Surgery, 2001, 25 , $10-14$.

Carmena D., Benito A. \& Eraso E. Antigens for the immunodiagnosis of Echinococcus granulosus infection: an update. Acta Tropica, 2006, 98, 74-86.

Coltorti E.A. Standardization and evaluation of an enzyme immunoassay as a screening test for the seroepidemiology of human hydatidosis. American Journal of Tropical Medicine and Hygiene, 1986, 35, 1000-1005.

Doiz O., Benito R., Sbihi Y., Osuna A., Clavel A. \& GomezLus R. Western blot applied to the diagnosis and post-treatment monitoring of human hydatidosis. Diagnostic Microbiology and Infectious Disease, 2001, 41, 139-142.

Force L., Torres J.M., Carrillo A. \& Busca J. Evaluation of eight serological tests in the diagnosis of human echinococcosis and follow-up. Clinical Infectious Diseases, 1992, 15, 473-480.

Gadea I., Ayala G., Diago M.T., Cunat A. \& de lomas J.G. Immunological diagnosis of human cystic echinococcosis: utility of discriminant analysis applied to the enzymelinked immunoelectrotransfer blot. Clinical and Diagnostic Laboratory Immunology, 1999, 6, 504-508.

Kanwar J.R., Kaushik S.P., Sawhney I.M., Kamboj M.S., Mehta S.K. \& VINAYAK V.K. Specific antibodies in serum of patients with hydatidosis recognised by immunoblotting. Journal of Medical Microbiology, 1992, 36, 46-51.

Li J., Zhang W.B. \& McManus D.P. Recombinant antigens for immunodiagnosis of cystic echinococcosis. Biological Procedures Online, 2004, 6, 67-77.

Liance M., Janin V., Bresson-Hadni S., Vuttton D.A., Houin R. \& Piarroux R. Immunodiagnosis of Echinococcus infections: confirmatory testing and species differentiation by a new commercial Western Blot. Journal of Clinical Microbiology, 2000, 38, 3718-3721.

Mamuti W., Yamasaki H., SaKo Y., NaKaya K., NaKaO M., LighTOWLERS M.W. \& ITO A. Usefulness of hydatid cyst fluid of Echinococcus gramulosus developed in mice with secondary infection for serodiagnosis of cystic echinococcosis in humans. Clinical and Diagnostic Laboratory Immunology, 2002, 9, 573-576.

McManus D.P., Zhang W., Li J. \& Bartley P.B. Echinococcosis. Lancet, 2003, 18, 1295-1304.

McManus D.P. Molecular discrimination of taeniid cestodes. Parasitology International, 2006, 55 (Suppl.), S31-S37.

SBIHI Y., JANSSEN D. \& OsunA A. Specific recognition of hydatid cyst antigens by serum $\operatorname{IgG}, \operatorname{IgE}$ and $\operatorname{IgA}$ using western blot. Journal of Clinical Laboratory Analysis, 1997, $11,154-157$. 
SCHANTZ P.M. \& GotTstein B. Echinococcosis (hydatidosis), in: Immunodiagnosis of parasitic diseases. Walls K.W. \& Schantz P.M. (eds), Academic press, Orlando, 1986, 69-107.

Shambesh M.K., Craig P.S., Gusbi A.M., Echtuish E.F. \& Wen H. Immunoblot evaluation of the 100 and $130 \mathrm{kDa}$ antigens in camel hydatid cyst fluid for the serodiagnosis of human cystic echinococcosis in Libya. Transactions of The Royal Society of Tropical Medicine and Hygiene, 1995, 89, 276279.

Todorov T., Vutova K., Vachkov P., Boeva V., Mechkov G., Handjiev S. \& Donev S. Double aldehyde stabilisation of erythrocytes in the indirect hemagglutination for echinococcosis. Parasitology International, 2003, 52, 203-207.

Verastegui M., Moro P., Guevara A., Rodriguez T., Miranda E. \& Gilman R.H. Enzyme-linked immunoelectrotransfer blot test for diagnosis of human hydatid disease. Journal of Clinical Microbiology, 1992, 30, 1557-1561.

Wattal C., Malla N., Khan I.A. \& Agarwal S.C. Comparative evaluation of enzyme-linked immunosorbent assay for the diagnosis of pulmonary echinococcosis. Journal of Clinical Microbiology, 1986, 24, 41-46.

Wen H. \& Craig P.S. Immunoglobulin G subclass responses in human cystic and alveolar echinococcosis. American Journal of Tropical Medicine and Hygiene, 1994, 51, 741748.

Zarzosa M.P., Orduna-Domingo A., Gutierrez P., Alonso P., Cuervo M., Prado A., Bratos M.A., Garcia-Yuste M., Ramos G. \& RODriguez-Torres A. Evaluation of six serological tests in diagnosis and postoperative control of pulmonary hydatid disease patients. Diagnostic Microbiology and Infectious Disease, 1999, 35, 255-262.

Reçu le 13 décembre 2005

Accepté le 5 juillet 2006 